\title{
Síndrome do Anticorpo Antifosfolípide e Endometriose
}

\section{Antiphospholipid Syndrome and Endometriosis}

\author{
Leonardo Schmidt ${ }^{(1)}$, Claudine J. C. Burkiewicz ${ }^{(1)}$, Paulo C. Pastro ${ }^{(2)}$, Marilia Barreto Silva $^{(2)}$, \\ Thelma L. Skare ${ }^{(2)}$

\section{RESUMO}

\section{ABSTRACT}

Descreve-se um caso de síndrome de Sneddon associada à presença de anticorpos antifosfolípides em uma paciente jovem com endometriose. Os autores analisam a associação destas duas enfermidades.

Palavras-chave: endometriose, acidente vascular cerebral, livedo reticularis e síndrome do anticorpo antifosfolípide.

\section{INTRODUÇÃO}

Existe considerável evidência na literatura de que a endometriose se faz acompanhar de manifestações de auto-imunida$\mathrm{de}^{(1-4)}$. Casos de artrite reumatóide, lúpus eritematoso sistêmico, síndrome de Sjögren e hipotireoidismo têm sido associados a esta doença pélvica inflamatória, na qual existe um crescimento de tecido endometrial fora do útero ${ }^{(1)}$. Distúrbios auto-imunes mais sutis, como presença de fator antinuclear (FAN), anticorpos anti-ribonucleoproteínas, consumo de complementos e presença de anticorpos anticardiolipinas também têm sido detectados nesta enfermidade ${ }^{(2)}$. Abrão et a ${ }^{(3)}{ }^{\text {descreveram um }}$ aumento preferencial de anticorpos anticardiolipina do grupo $\operatorname{IgM}$ nestas pacientes. Outros autores se preocuparam com o fato de que a presença destes auto-anticorpos possa contribuir para a falha reprodutiva encontrada na endometriose ${ }^{(4)}$.

Descrevemos aqui um caso de síndrome de Sneddon associado à endometriose numa paciente jovem, para demonstrar a associação desta enfermidade com a presença de auto-anticorpos e, assim, chamar a atenção da comunidade de reumatologistas para esta associação, que não é muito reconhecida.

\section{DESCRIÇÃO DE CASO}

Paciente feminina, 22 anos, branca, casada, foi trazida pelos familiares ao Pronto Socorro do Hospital Universitário Evangélico de Curitiba (HUEC) porque se encontrava afásica e hemiparética. Segundo familiares, a paciente acordou, naquela manhã, com dificuldades para mobilizar o lado direito
We describe a patient with Sneddon's syndrome associated with antiphospholipid antibodies and endometriosis. The authors analyze the association of these two diseases.

Keywords: endometriosis, cerebro vascular disorder, livedo reticularis, antiphospholipid syndrome.

do corpo e para falar. Nos antecedentes mórbidos pessoais, existia uma história de paralisia facial periférica havia um ano. Os antecedentes obstétricos mostravam que ela era gesta I, para I, sem histórias de abortamentos. Fumava cerca de dez cigarros por dia desde a adolescência.

Ao exame físico, notava-se: pressão arterial $=150 \times 90$ $\mathrm{mmHg}$; pulso $=88$; temperatura $=36^{\circ} \mathrm{C}$. A ausculta de caróti das e vertebrais era normal. As bulhas cardíacas estavam rítmicas e normofonéticas e a ausculta pulmonar não tinha particularidades. O abdome era plano, indolor e sem visceromegalias. Existia livedo reticularis em ambos os membros inferiores (Figura 1). No exame neurológico, encontrava-se afasia mista com predomínio de afasia de expressão e discreta dificuldade de compreensão. Existia hemiparesia de dimídio direito. As pupilas eram isocóricas e fotorreagentes. Reflexos tendinosos +/- simétricos; reflexo cutâneo plantar era indiferente à direita e em retirada à esquerda. No fundo do olho existia uma cicatriz de coriorretinite à esquerda, sem outras lesões ativas.

A investigação laboratorial mostrou: hematócrito de $37 \%$, leucócitos de $6.400 / \mathrm{mm}^{3}$ e 70.000 plaquetas $/ \mathrm{mm}^{3}$. A velocidade de hemossedimentação (VHS) era de $57 \mathrm{~mm}$ na primeira hora. Creatinina de $1.06 \mathrm{mg} / \mathrm{dl}$; látex $<8 \mathrm{U} / \mathrm{ml}$; FAN negativo, VDRL de $1: 4$, com FTA Abs negativo. KPTT de 42,9 segundos. Anti-HIV, HBsAg e anti-HCV eram negativos. Anticardiolipinas (aCl) IgG>120 GPL, aCl Ig M=19 MPL. Dosagens de antitrombina 3, proteína C e proteína $S$ estavam normais. Parcial de urina e raio $\mathrm{X}$ de tórax também foram normais. Uma ecocardiografia mostrou fração de ejeção de 0,76 ; encurtamento percentual de $37 \%$ e uma

Serviço de Reumatologia do Hospital Universitário Evangélico de Curitiba (HUEC). Recebido em 05/05/06. Aprovado, após revisão, em 02/09/06.

1. Médico Residente do Serviço de Reumatologia HUEC.

2. Médico(a) do Serviço de Reumatologia do HUEC.

Endereço para correspondência: Thelma L. Skare, Rua João Alencar Guimarães, 796, CEP 8310-420, Curitiba, PR, Brasil, e-mail: tskare@onda.com.br 


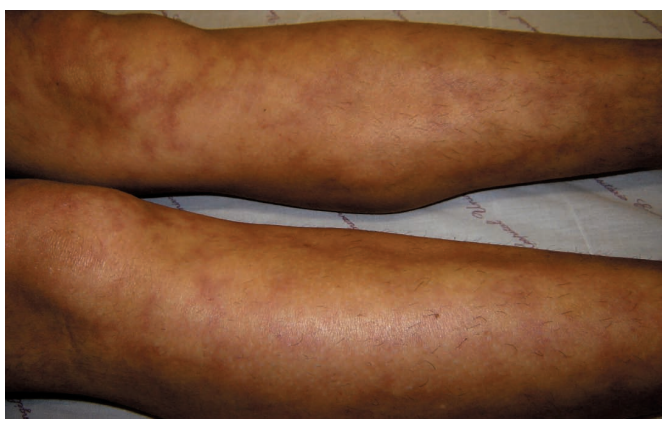

Figura 1 - Livedo reticularis em membros inferiores.

válvula mitral com insuficiência moderada e vegetações no folheto posterior. Uma tomografia de crânio demonstrou isquemia aguda em região fronto-têmporo-parietal à esquerda (Figura 2). Hemoculturas foram negativas.

A paciente foi tratada com anti-hipertensivos (losar$\tan$ ) e anticoagulantes (inicialmente heparina, seguido de cumarínicos). Recuperou-se, parcialmente, dos distúrbios da fala e da paresia, sendo acompanhada ambulatorialmente pela reumatologia e pela fonoaudiologia.

Nove meses depois do internamento, a paciente passou a apresentar crises de dor abdominal intensa em cólicas acompanhadas de náuseas e vômitos. Observou-se uma queda no hematócrito de $38 \%$ para $34,3 \%$. Investigação mostrou uma massa em topografia de ovário direito com características mistas (sólidas e líquidas). Foi submetida à laparotomia exploradora, sendo encontrados uma trompa avermelhada e congesta e um ovário com um cisto hemorrágico à direta, que foram retirados. O exame histopatológico do material revelou presença de endometriose em trompa e um cisto endometriótico com hemorragia em ovário direito.

Atualmente (oito meses após a cirurgia), a paciente encontra-se assintomática do ponto de vista abdominal, porém ainda com hemiparesia à direita e afásica. Os títulos de anticardiolipinas continuam altos ( $\mathrm{aCl}$ Ig G $>100$ GPL e aCl IgM de 6,8 MPL) e a anticoagulação oral vem sendo mantida.

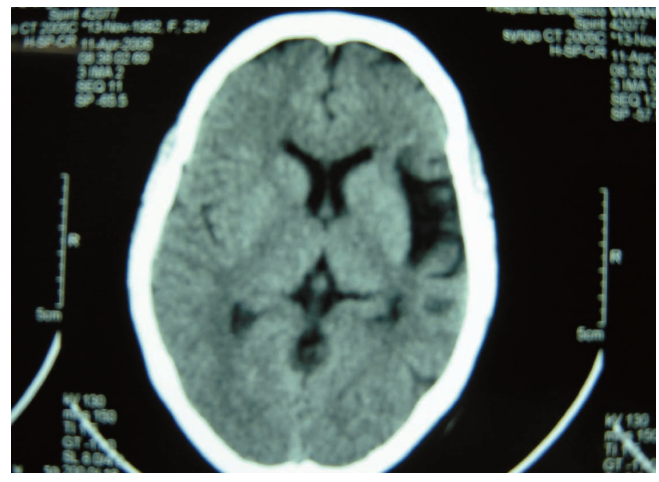

Figura 2 - TC mostrando lesões isquêmicas em região fronto-têmporo-parietal.

\section{DISCUSSÃO}

A síndrome de Sneddon é descrita como a associação de acidentes vasculares cerebrais e livedo racemosa ${ }^{(5,6)}$. Embora a descrição inicial da síndrome de Sneddon considere o livedo como racemoso, achados de livedo reticularis também têm sido atribuídos a esta síndrome ${ }^{(7)}$. O livedo racemoso caracteriza-se clinicamente por lesões cutâneas rendilhadas, irregulares, grandes e interrompidas, ao passo que a forma do livedo reticularis é mais regular, tem um padrão mais nítido, violáceo e em formato de rede ${ }^{(5,7)}$. Os achados neurológicos da síndrome de Sneddon compreendem acidentes vasculares transitórios, acidentes vasculares cerebrais, cefaléias, deterioração mental, convulsões e demência ${ }^{(5)}$. Embora a síndrome de Sneddon tenha sido descrita como uma doença que cursa com deterioração progressiva, este aspecto prognóstico não tem sido verificado por todos os autores ${ }^{(5)}$.

Em um subgrupo de pacientes com síndrome de Sneddon têm sido encontrados anticorpos antifosfolípides, sejam eles pertencentes à forma primária da doença ou à forma secundária ${ }^{(7,8)}$. Os anticorpos antifosfolípides estão associados não só com a síndrome de Sneddon mas, possivelmente, com uma grande variedade de outros achados neurológicos que estão resumidos na Tabela 1 .

Do ponto de vista fisiopatológico, estes achados neurológicos têm sido atribuídos à trombose ou embolia e, também, à ligação dos anticorpos com mielina ${ }^{(8)}$. É interessante notar que alguns destes achados neurológicos da síndrome dos anticorpos antifosfolípides guardam relação com o perfil hormonal estrogênico da paciente, como é o caso da coréia. Esta tem sido precipitada pelo uso de anticoncepcionais, gravidez ou puerpério ${ }^{(8)}$. A própria síndrome de Sneddon é de preponderância feminina ( 3 mulheres: 1 homem), com um aumento de risco para eventos cerebrais isquêmicos durante gravidez e uso de anticoncepcionais ${ }^{(9)}$. Curiosamente, a síndrome de Sneddon tem sido descrita em casos de tratamento com gonadotrofinas para infertilidade ${ }^{(9)}$.

Presença de anticorpos anticardiolipina tem sido descrita em pacientes com endometriose ${ }^{(3,7)}$ junto com outras anormalidades do sistema imune, tais como presença do FAN, anticorpos anti-ribonucleoproteína, consumo de complementos e achados clínicos de fadiga crônica, fibromialgia, artralgias e mialgias ${ }^{(1,2,}$ ${ }^{10)}$. Segundo Pasoto et al ${ }^{(10)}$, pacientes com endometriose têm uma prevalência de queixas musculoesqueléticas semelhante à de pacientes com LES. Sinaii et $\mathrm{a}^{(1)}$ encontraram aumento na prevalência de hipotireoidismo, alergias, artrite reumatóide, síndrome de Sjögren e fibromialgia nestes pacientes ${ }^{(1)}$. 
TABELA 1

ACHADOS NEUROLÓGICOS ASSOCIADOS À SÍNDROME DO ANTICORPO ANTIFOSFOLÍPIDE ${ }^{(8)}$

\begin{tabular}{|c|c|}
\hline Cefaléias; & Distonia-parkinsoniana; \\
\hline Síndrome "esclerose múltipla-like"; & Síndrome de Guillain Barré; \\
\hline Perda auditiva neurossensorial; & Disfunção cognitiva; \\
\hline Síndromes oculares; & Mielite transversa; \\
\hline Coréia; & Demência; \\
\hline Epilepsia; & $\begin{array}{l}\text { Desordens psiquiátricas (depressão, } \\
\text { psicoses). }\end{array}$ \\
\hline
\end{tabular}

Alterações imunes desempenham um papel no início e no desenvolvimento da endometriose. Acredita-se que o tecido endometrial ectópico resulta de implantação de células endometriais provenientes de um fluxo menstrual retrógrado ${ }^{(4)}$. Estas células não são destruídas porque ou a paciente é geneticamente programada para não responder aos antígenos endometriais ou porque o refluxo é tão abundante que se sobrepuja à capacidade de limpeza do sistema imune ${ }^{(4)}$. Além disto, estas células anômalas parecem ser protegidas pelo peritôneo - o que favorece sua permanência através da síntese de moléculas de adesão e de citocinas angiogênicas. As células não destruídas causam inflamação e ativação macrofágica. Os macrófagos ativados apresentam antígenos endometriais às células $\mathrm{T}$ que cooperam com as células B para a síntese de auto-anticorpos ${ }^{(4)}$. Estrógenos facilitam a evolução da doença por favorecerem a proliferação das células endometriais e por diminuírem a ação de células $\mathrm{NK}^{(4)}$. No tratamento da endometriose inclui-se a formação de um ambiente hipoestrogênico ${ }^{(11)}$.

Não existe correlação entre a gravidade da endometriose e o grau de formação de auto-anticorpos, mas tem sido encon-

\section{REFERÊNCIAS}

1. Sinaii N, Cleary SD, Ballweg ML, Niemann LK, Stratton P: High rates of autoimmune and endocrine disorders, fibromyalgia, chronic fatigue syndrome and atopic diseases among women with endometriosis: a survey analysis. Hum Reprod 17: 2715-24, 2002.

2. Taylor PV, Maloney MD, Skerrow SM, Nip NM, Parmar R, Tate G: Autoreactivity in women with endometriosis. Br J Obstet Gynecol 98: 680-4, 1991.

3. Abrao MS, Podgaec S, Filho BM, Ramos LO, Pinotti JA, de Oliveira RM: The use of biochemical markers in the diagnosis of pelvic endometriosis. Hum Reprod 12: 2523-7, 1997.

4. Vinatier D, Dufour P, Oosterlynck D: Immunological aspects of endometriosis. Hum Reprod Update 2: 371-84,1996.

5. Boesch SM, Plörer AL, Auer AJ, Aichner FT, Felber SR, Fepp NT: The natural course of Sneddon syndrome: clinical and magnetic resonance imaging in a prospective six year observation study. J Neurol Neurosurg Psychiatry 74: 542-4, 2003.

6. Sinharay S: Sneddon's syndrome: additional neurological features trada uma correlação entre a presença destes auto-anticorpos, infertilidade e risco de abortamento ${ }^{(4)}$.

O conceito da associação entre endometriose e doenças auto-imunes, como a do caso descrito, é importante para o reumatologista quando se reflete sobre o fato de que, no diagnóstico diferencial de artralgias, mialgias e presença de autoanticorpos, a endometriose deve ser considerada. Além disto, o conhecimento da associação entre estas formas de doenças auto-imunes leva o clínico a estabelecer uma avaliação mais precisa das diferentes situações nosológicas que potencialmente afetam o paciente. Uma terceira questão a ser levantada é a de que, em pacientes com endometriose e falha reprodutiva, é necessário que se estabeleçam os exatos mecanismos desta falha (se infertilidade pela endometriose ou abortamentos de repetição por antifosfolípides), uma vez que as formas de tratamento são diferentes. Também o papel favorecedor dos estrógenos precisa ser melhor estudado, tanto no contexto da endometriose como no das manifestações neurológicas da síndrome dos anticorpos antifosfolípides. Por último, interferências entre os tratamentos das duas doenças devem ser adequadamente apreciadas. No caso relatado, acreditou-se que o componente hemorrágico encontrado no local de implantação da endometriose foi favorecido pelo uso da anticoagulação usada para tratamento da síndrome de Sneddon.

$\mathrm{Na}$ descrição feita, os anticorpos anticardiolipina mantiveram-se positivos após a ressecção do foco de endometriose. Isto sugere que síndrome de Sneddon e endometriose são apenas doenças auto-imunes associadas, e que não existe nexo causal entre as mesmas.

Declaramos a inexistência de conflitos de interesse.

in antiphospholipid (Hugues') syndrome (letter). Postgrad Med J 79: 553, 2003.

7. Sangle S, D'Cruz DP, Hugues GRV: Livedo reticularis and pregnancy morbidity in patients negative for antiphospholipid antibodies. Ann Rheum Dis 64: 147-8, 2005

8. Sanna G, Bertolaccini ML, Cuadrado MJ, Khamashta MA, Hugues GRV: Central nervous system involvement in the antiphospholipid (Hugues) syndrome. Rheumatology 42: 20013, 2003.

9. Ellie E, Masson J, Julien J, Parneix L, Riyer R, Beylot C: Gonadotrophins, livedo reticularis and strokes. Stroke 20: 1377 8,1990 .

10. Pasoto SG, Abrão MS, Viana VS, Bueno C, Leon EP, Bonfa E: Endometriosis and systemic lupus erythematosus: a comparative evaluation of clinical manifestations and serological autoimmune phenomena. Am J Reprod Immunol 53: 85-93, 2005.

11. Nothinick WB: Treating endometriosis as an autoimmune disease. Fert Steril 76: 223-31, 2001. 